\title{
Teacher Competencies for Inclusive Education: Will Emotional Intelligence do Justice?
}

\section{OPEN ACCESS}

Manuscript ID:

EDU-2020-09013494

Volume: 9

Issue: 1

Month: December

Year: 2020

P-ISSN: 2320-2653

E-ISSN: 2582-1334

Received: 19.10 .2020

Accepted: 28.11.2020

Published: 01.12.2020

Citation:

Rajendran, Poornima, et al. "Teacher Competencies for Inclusive Education: Will Emotional Intelligence Do Justice?" Shanlax International Journal of Education, vol. 9, no. 1, 2020, pp. 169-182.

DOI:

https://doi.org/10.34293/ education.v9i1.3494

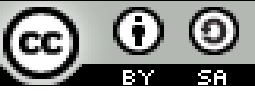

This work is licensed under a Creative Commons Attribution-ShareAlike 4.0 International License

\author{
Poornima Rajendran \\ Assistant Professor, Department of Education \\ Central University of Tamil Nadu (Neelakudi Campus), Thiruvarur, Tamil Nadu, India \\ https://orcid.org/0000-0001-8868-9372
}

\section{B.K. Athira}

Research Scholar, Centre for the Study of Social Systems

Jawaharlal Nehru University, New Delhi, India

\section{Elavarasi}

Research Scholar, Department of Education

Central University of Tamil Nadu (Neelakudi Campus), Thiruvarur, Tamil Nadu, India

\begin{abstract}
Purpose: The concept of inclusive education is moved from the homogeneous perspective to heterogeneous perspective in developed countries and even in developing countries, the discourses on inclusive education are argued from the diversity perspective. Many scholars (Florian, 2010; Slee, 2010; Meijer, 2003 and; Allan, 2011) who are researching on inclusive education debated and discussed that successful practice of inclusive education depends greatly on teacher competencies, albeit practicing inclusive education depends on many critical factors like attitudes, curriculum, resources, parental involvement, multidisciplinary orientation etc., Projects like 'Teacher Education for Inclusion (2009-2012)' discussed and framed various models of teacher competencies required for the successful practice of inclusive education. In this conceptual paper, the authors reviewed the dimensions /sub scales of emotional intelligence and deliberated its significance associated with teacher competencies that support them to practice inclusive education.

Approach: Even though there are various emotional intelligence models, the authors have chosen the Bar-On Model of Emotional Intelligence (2006) considering its wider usage across the country. Further, the author included the conceptual papers/research works accessible via open source for the review.

Significance: The present review makes the reader to understand and rationalize the significance of emotional intelligence for teachers (both pre and in-service) to develop their competencies for practicing inclusive education. On one hand, this review justifies the readers that emotional intelligence is related significantly and positively to increased adapted behaviour, higher quality social relationships, longer retention in one's professional life, better coping strategies and leadership skills that enhances individuals' intra and inter personal skills. On the other hand, the paper will deduce that the emotional intelligence in teachers will benefit them to meet the needs of diverse students in their classroom without any doubt.

Originality Value: The present review is a part of an ICSSR Major Research Project sponsored during the academic year 2017-18.
\end{abstract}

Keywords: Inclusive education, Teacher competencies, Emotional intelligence

\section{Conceptualizing Inclusive Education}

Over several decades, the concept of inclusive education was defined and argued with respect to special education perspective in most of the countries. No wonder that interpreting inclusive education with respect to special education perspective are backed up with several factors like 1) the inclusive education emerged as an alternative to special education/integrated education, 
2) it emerged as a rights based approach to the disabled students, 3) the concept itself is promoted by the organizations meant to educate special needs children and other factors like this. Discussing or even implementing inclusive education will be difficult for the professionals without the contributions from special education. Understanding the concept of inclusive education pose a challenge to everyone researching inclusive education (Loreman et al., 2014). Loreman et al., (2014) while conceptualizing inclusive education documented that it will be tricky defining inclusive education based on key features and problematic defining it as the removal of that which excludes and marginalizes. This is because that these factors vary from culture to culture and situation to situation.

Even though there are many factors causing barriers in implementing inclusion, conceptualizing the concept in a right sense itself is a barrier for successful inclusion. In the present decade, professionals discussed and debated inclusive education in terms of diversity perspective. This expanded view of inclusive education pave ways to look the concept as a whole of school issue. Also, it allows students to participate because of the issues arising not only out of disability but also other factors like gender, behaviour, poverty, culture and other factors. Considering the diverse perspective and the extensive review made by the author on defining inclusive education adapts the following definition given by UNESCO (2012):

"Education is not simply about making schools available for those who are already able to access them. It is about being proactive in identifying the barriers and obstacles learners encounter in attempting to access opportunities for quality education, as well as in removing those barriers and obstacles that lead to exclusion".

\section{Teacher Competencies for Inclusive Education}

Apart from the barriers arising out of conceptualizing inclusive education, the other barriers includes stereotypic attitudes, inaccessible curriculum, inadequate resources, teachers not adequately trained, lack of parental involvement and lack of multidisciplinary orientation (Poornima, 2012). Off all these factors, teacher competencies and the teachers' positive attitude are considered vital as at the end it is teachers who has to teach students with diverse nature in their classroom and implement the principles of inclusive education in true sense (Meijer, 2011). It was also documented that teachers are not adequately trained and lack competencies to practice inclusive education across the globe. This part of the paper specifically highlight relevant competencies required by teachers to practice inclusive education.

European Agency for the Development of Special Needs Education (2011) in the Teacher Education for Inclusion (TE4I) report summarized the key teacher competences highlighted by the majority of agency countries as most relevant to the development of inclusive practice:

Reflecting on their own learning and continually seeking out information to overcome challenges and support innovative practice;

Attending to the well-being of learners, taking responsibility for meeting all learning and support needs and ensuring a positive ethos and good relationships;

Collaborating with others (professionals, parents) to assess and plan an engaging curriculum to meet the diverse needs of learners, attending to issues of equality and human rights;

Using a variety of 'inclusive' teaching methods and, group and independent work appropriate for the aims of learning, the learners' age, and their abilities/ stage of development and evaluating learning and the effectiveness of methods used;

Addressing language learning in multi-lingual contexts and valuing cultural diversity as a resource.

In a nutshell, the areas of teacher competencies highlighted by TE4I include: Valuing learner diversity, Supporting all learners, Working with others, and Personal, professional development. Poornima (2012) reviewed various frameworks and framed a comprehensive competency framework that includes attitudes and beliefs, knowledge and understanding; teaching and training; intra and interpersonal relationships and; research competencies of teachers with particular reference to inclusive education. 


\section{Drawing Emotional Intelligence Competency Framework}

The significance of emotional intelligence is researched in almost all disciplines. The term gained and gaining acceptance as its end product is both personally and professionally rewarding its stakeholders. Yate (1977) in his research, found that different jobs require different levels of Emotional Quotient (EQ) and listed various jobs based on the level of EI they require for success and satisfaction. Special education teacher requires the highest level of EQ to deal with special needs children (Poornima, 2012). It is not only special needs education teachers but also teachers in general who have to teach students with diverse nature needs varied competencies. They require a new approach where they have to manage the classroom climate, teach qualitatively, adapt to the social changes, and should exhibit good decisionmaking skills. The challenge of performing the tasks in teaching diverse students is that they need a high degree of emotional stability, the flexibility of procedures and routines, freedom to act according to the student needs and support from their colleagues. Considering its significance, the author has taken this variable to justify its implications to the teachers in practicing inclusive education. The forthcoming section of this paper will identify the relevance of emotional intelligence dimensions that aid teachers in enhancing their competencies for practicing inclusive education.

\section{EI Dimensions for Teacher Competencies}

Scholars researching emotional intelligence interpreted the variable in ability, mixed and in trait forms. Among these three models, the mixed model of EI gained wide acceptance. Mayer and Salovey (1997), proponents of the ability model of EI postulated that emotional intelligence involves the ability to perceive accurately, appraise and express emotion, the ability to access and generate emotional knowledge, and the ability to regulate emotion to promote emotional and intellectual growth. The mixed model given by Goleman (1998) includes over 25 characteristics of emotional intelligence, including everything from emotional self-awareness to such diverse qualities as teamwork and collaboration, service orientation, initiative, and achievement motivation. According to Bar-On (2005):

"Emotional-social intelligence is an array of interrelated emotional and social competencies, skills and behaviors that determine how well we understand and express ourselves, understand others and relate with them, and cope with daily demands, challenges and pressures."

The author reviewed various definitions and models of emotional intelligence and adapted the EI model given by Bar-On in 2006. This mixed model of EI consists of the following 5 major dimensions and 15 sub-factors.

\begin{tabular}{|l|l|l|l|l|}
\hline \multicolumn{1}{|c|}{ Intrapersonal } & \multicolumn{1}{|c|}{ Interpersonal } & $\begin{array}{c}\text { Stress } \\
\text { Management }\end{array}$ & \multicolumn{1}{|c|}{ Adaptability } & General Mood \\
\hline Self-Regard & Empathy & Stress tolerance & Reality testing & Optimism \\
\hline Emotional Self Awareness & Social Responsibility & Impulse control & Flexibility & Happiness \\
\hline Assertiveness & Interpersonal Relationship & & Problem Solving & \\
\hline Independence & & & & \\
\hline Self-actualization & & & & \\
\hline
\end{tabular}

\section{Intrapersonal}

This meta-factor of emotional-social intelligence comprises self-regard, emotional self-awareness, assertiveness, independence and self-actualization (Bar-On, 2013). It is an ability to be aware of one's own emotions and express those feelings. This factor in particular, will help the teachers to be good in their communication, understanding, listening, nonverbal communication which helps them to gain self- confidence in due course of time.

\section{Self- Regard}

It refers to “. ... ability to look inward and accurately perceive, understand and accept oneself" (Bar-On, 2013). Self- regard is having the ability to accurately look at and evaluate oneself leading to respecting and accepting oneself. Self-acceptance essentially is the way to accept one's positive/negative qualities, 
strengths/weaknesses and limitations/ possibilities. Bar-on (2013) opined that people lacking self-regard would have personal inadequacy and inferiority that can further contribute to frustration, depressive mood and difficulty in accomplishing personal goals and enjoying life. Jorfi, Yaccob and Shah (2010) observed that an individual having high self-regard would possess high idea of oneself. Individuals with low self-regard observe themselves as not important and lower, making them feel negative (Jorfi et al., 2010). The same authors have analyzed that selfregard has a high relationship with communication especially communication effectiveness.

Robert (2018) in his article discussed the importance of teachers in fostering students' sense of dignity and self-worth. The teachers with high level of self-esteem will be confident, relaxed and respectful towards students. Further, they seem to be flexible, exploratory in their approach to teaching and they can make changes in students not only through the use of systematic activities but also through the establishment of particular caring relationships with students (Leminen, 2002).

Also, Leminen (2002) documented the results of Chapman, 1988; Hattie and Marsh, 1996; Rothman and Cosden, 1995; Ulvinen, 1998 where they noted a significant relationship between the self-concept and academic achievement of children. These results lay emphasis on the significance of fostering selfconcept in children.

Further, Leminen (2002) noted that children who marked learning difficulties in school frequently have low levels of self-esteem. Levels of self-esteem held by teachers can influence the development of high self-esteem in children.

\section{Emotional Self-awareness (ESA)}

ESA is defined as one's ability to be aware of, identify and understand one's own emotions. Emotional self-awareness is to know what individuals are feeling and why and to know what causes these feelings (Bar-On, 2013). Gold and Roth (1993, Pp. 141 as cited in Richardson, and Shupe, 2003) defined self-awareness as a process of getting in touch with their feelings and behaviors. The person who is aware of their own emotions are self-determined to work towards their goals.
Field and Hoffman (1994) described selfdetermination as knowing one's strengths, limitations, needs, and preferences well enough to analyze options and goals and to determine a clear vision for one's future (as cited in Michali, 2014). Self-determined individuals choose their goals by assessing their needs and by acting in ways to meet those goals. Wehmeyer, Kelchner, and Richards (1996) perceived that the self-determined individual would be characterized with autonomous behavior, self-regulated personality, will empower psychologically and involve in self-realization (as cited in Michali, 2014).

Richardson, and Shupe (2003) observed that increased self-awareness in teachers is a two-way process where on the one hand it involves a more accurate understanding of how students affect their emotional processes and behaviors. On the other hand it deals with how teachers affect students, as well. Also, they stressed the importance of selfawareness in teachers working with exceptional students as they are seldom unaffected by students' behavior, but often the students reflect the best and worst in teachers. Sabrina and Sansrisna (2017) found that teachers practicing inclusive education believed that their self-reflection and awareness to be an important factor that helped them to practice inclusion.

\section{Assertiveness}

Assertiveness is "an ability to effectively and constructively express our feelings and oneself in general, which is based on effective self-awareness" (Bar-On, 2013). According to Bar-on, assertiveness is composed of three basic components, such as the ability to express our feelings, the ability to express beliefs/opinions and the ability to stand up for our rights and not to allow others to bother or take advantage. An individual with assertive nature will tend to express positive and negative feelings, refuse unreasonable requests, take the initiative, apologize, deal with personal faults, and stand up for personal rights (Vagos and Pereira, 2010). Likewise, Milovanovi, Miladinovi and Stojanovi (2016) noted that assertiveness includes a sense of security in social interactions, resolute rejection of unjustified requests, adequate opposition, the clear expression of ideas, independent decision-making with respect 
for others, openness and honesty towards others, an ability to listen to and, understand and praise others.

With this significance, one can deliberate that assertiveness is necessary for classroom management. To create a positive learning climate, the teachers should take care of 1) the management of social situations in the classroom, 2) management of student behaviour and 3) organization of the group's work (Milovanovi et al., 2016), for which assertive skill in teachers is essential. This will help them to be persistent in their efforts to react to inappropriate student behavior in an adequate manner which includes a sense of security, ability to control and a desire to solve the problem (Edwards, 2005 as cited by Milovanovi et al., 2016). Also, Milovanovi et al. (2016) documented that assertiveness in teachers reduces social anxiety, stress and increases their selfrespect. Further, Aliakbari and Bozorgmanesh (2015) noted a positive relationship between the assertive qualities of a teacher with students' performance.

Furthermore, the scope of a teacher being assertive is related to the 'bargaining power' of a teacher with the administrators or decision-makers. This assertive quality then becomes crucial for a teacher to make their voice heard, when they collaborate with the surroundings.

Similarly, the research from Martínez, Justicia, and Fernández (2006) revealed that both selfassertiveness and hetero-assertiveness of teachers impacted group cohesion. The research concluded that the assertiveness of teachers positively influences the development of students' social competence, and more specifically, those students who manipulate and take advantage of others for their benefit.

\section{Independence}

Bar-On (2013) defined independence as “one's ability to be self-reliant and free of emotional dependency on others". Bar-On identifies it to be an "ability to function autonomously" and as a facilitator rather than an integral factorial component of EI. The concept of teacher autonomy as noted by Sprenger and Wadt (2008), is teachers' capacity, willingness and right to make informed decisions about classroom tasks, where the teacher is conscious of his/her potential and his students' potential to produce changes in their cultural, social and political context.
Greenway, McCollow and Hudson (2013) observed that autonomy in teachers would result in being accountable. Sprenger and Wadt (2008) pointed out that if teachers become more autonomous, they will probably feel confident to make decisions.

One of the major limitations faced by teachers is their dependency on the administration in decision making. Also, the Guardian (11th Feb 2013) discussed the perception of teachers on their autonomy, where it was observed that the teachers are not trusted and not allowed to plan effectively for their children they teach. At a certain point in time, teachers should be in a position to be self-reliant in planning and making important decisions, as in practicing inclusive education, implementation of uniform rules and regulations may fail to work owing to diversity. The dependency on the decision-makers makes the teachers inefficient to function properly. This limitation will hinder them in 1) framing the need-based syllabus for diverse natured students, 2) implementing specific pedagogical practices, 3) collaborate with other professionals.

\section{Self-actualization}

It refers to "one's ability to set personal goals and the drive to achieve them to actualize their potential" (Bar-On, 2013). According to him, this can enable an individual to strive towards maximum development of his/her competencies, skills etc. According to Jena and Dorji (2016), a self-actualized person will possess qualities like acceptance, realism, problem centering, spontaneity, autonomy and solitude. These are essential for a teacher while practicing inclusive education. The quote by Rapheal and Varghese (2014) highlights that "self-actualized teachers are more likely to ensure effectiveness in their profession" and this s strengthens the need of self- actualized teachers in inclusive education.

Andrew (2011) stressed that self-actualization in teachers would result in practicing reflective practices in the classroom the . In reflective teaching practice, teachers will have opportunities to revisit their teaching experiences to increase their awareness of what they do, to understand it, challenge it, modify it, and develop from it. By reflecting in the act of teaching, helps to make continual, spontaneous decisions on how best to proceed at any given moment. In inclusive classrooms, reflective teaching 
practice has evolved as a significant strategy for teachers to be successful in their teaching-learning process.

Similarly, one can remember the significance of self-actualisation given by Abraham Maslow. According to him self-act, utilization is selfdiscovery, self-reflection, self-realization and selfexploration. It means how one to attain perfection and it is a process of differentiating good qualities from the bad in oneself and helping others (Maslow, 1970).

\section{Interpersonal}

This meta-factor of emotional intelligence comprises empathy, social responsibility and interpersonal relationship (Bar-On, 2013). It relates most importantly to social awareness, skills and interaction. This factor is primarily concerned with one's ability to understand others' feelings, emotions, needs and facilitate an individual to maintain cooperative, purposeful, mutually satisfying relationships.

\section{Empathy}

This interpersonal sub-factor is defined as the ability to be aware of and understand how others feel (Bar-On, 2013). Partridge (2018) quoted that "Empathy is a crucial means through which diversity is appreciated". Empathy means to be preoccupied with the thoughts and feelings of other people, putting oneself in their place, trying to think like them. According to BarOn-Cohen and Wheelwright (2004) empathy, is about spontaneously and naturally tuning into the other person's thoughts and feelings, whatever these might be (as cited in Stojiljković, Djigić and, Zlatković, 2012). According to Tettegah and Anderson (2007), empathy is an important disposition for educators to facilitate positive interactions among students. The same authors stated that teaching empathy is the capability to express concern and take the perspective of a student, and it involves cognitive and affective domains. An empathetic attitude in teachers helps them in learning about students feeling and embracing students' differences (Amoriello, 2017).

Stojiljković et al. (2012) noted that emotional stability and empathic sensitivity in teachers is considered as the most important factor in creating the overall atmosphere in the classroom. Also, they documented that the empathetic attitude in teachers will result in students feeling pleasure, free, adopted and involved, respected and understood. They found that the degree of empathy in teachers will contribute to the successful filling of their professional roles. Likewise, Parchomiuk (2018) analyses that empathy in teachers have resulted in more positive and favorable attitude towards an individual with disabilities.

Parchomiuk (2018) documented that people with higher levels of empathy: 1) are more open to getting acquainted with members of the other group (the disabled), including their capabilities and limitations, 2) show greater sensitivity (the ability to empathize with and show compassion), 3) are more able to understand others, 4) are more willing to work for others, that may: 1) reduce tendency the to form stereotypes and prejudices, 2) reduce negative feelings in relationships with persons with disabilities and their negative assessment, increase positive feelings and assessments, 3) foster the formation of positive expectations towards disabled people, 4) increase the power of motivation to contact with people with disabilities.

\section{Social Responsibility}

Social responsibility is defined as an "ability to identify with social groups, among friends, at work and in the community, and to cooperate with others in a constructive and contributing manner" (BarOn, 2013). He underlines it to be the contributing factor towards community oriented responsibilities and organizational goals. Social responsibility is the capacity to demonstrate ourselves as cooperative, contributing and constructive members of our social group. Pantic'and Florian (2015) stressed the importance of teachers to become agents of change for successful inclusion and social justice. Teachers as agents of inclusion and social justice emphasize the need to develop teachers' capacity for working with other agents to remove the structural and cultural barriers for some students' learning and participation. Also, this can be achieved by nurturing commitment t to social justice as part of teachers' sense of purpose (Pantic'and Florian, 2015).

According to Slee (2010), one of the most relevant areas of competence for promoting the inclusive 
practice in teacher education is student teachers' understanding of how the different social forces influence exclusion and disadvantage. Edwards (2010) pointed out that tea coaching involves taking mutual responsibility for joint actions that requires teachers and other actors to negotiate professional boundaries and work flexibly (as cited by Pantic'and Florian, 2015). Teachers involved in promoting inclusive education should be aware of equity, equality \& should be committed to education for all.

\section{Interpersonal Relationship}

Bar-On (2013) refers to this inter personal sub factor as one's ability to establish and maintain mutually satisfying relationships and relate well with others. Mutual satisfaction describes meaningful social interactions that are potentially rewarding and enjoyable for those involved. On the one hand, this relationship of (i) teachers and students and on the other hand (ii) teachers with other members of the school and local community will be reflected in innumerable ways in the lives of the students. This social skill is not only associated with the desirability of making relations but with the ability to feel at ease, comfortable and to be aware of emotions in such relationships. So this important sub-factor of emotional intelligence help to remove systemic barriers that persist in inclusion. Fan (2010) found a significant relationship between teacher-students' interpersonal relationship and students' academic achievements in social studies. Similarly, Opić, (2016) reviewed and found that the relationship between the teacher and the pupil is closely associated with the student's success and learning in school. Also, Opić, (2016) documented the behaviors in teachers like persistence, patience, listening, and encouragement of the student's inclusion in the teaching process, and at the same time the teachers action towards the student's education and development of his or her competences as an essential components for cooperation.

Minondo, Meyer and Xin (2001) suggested five major role components: (a) instructional; (b) school support; (c) liaison; (d) personal support; and (e) one-to-one in-class support, in which relationship and cooperation with others are considered as one of the significant roles to be played by teaching assistants involved in inclusive education.
Further, teachers in addition to managing the relationship with the students should also accomplish sustainable relationship with para-professionals, parents, fellow teachers, special education teachers, community people, administrators, researchers, policy makers etc., for establishing collaborative partnerships for successful inclusion.

\section{Stress Management}

This meta-factor comprises stress tolerance and impulse control and it is primarily related to emotional management and control. Researches (Johnson and Cooper, 2005) show that teaching is a stressful profession. Similarly, teaching special need students are considered more stressful (Billingsley, 2003; Reddy, 2007; Poornima, 2012). Other than the organizational stress, teachers are prone to encounter numerous other stressors include simultaneous management of students with disabilities and other members of the class; lack of time; the students' behavioral problems; non-acceptance of a disabled student by his classmates; lack of training in inclusion and special education (Forlin, 2001); teaching unmotivated students, sustaining discipline in the classroom, demanding workload, being exposed to frequent changes, being evaluated by others, undergoing difficult or challenging relationships with colleagues and administration and poor working conditions (Abu-Alhija, 2015). To overcome and manage their negative emotions, teachers should look for various ways to manage stress.

\section{Stress Tolerance}

Stress tolerance is defined as "an ability to effectively and constructively manage emotions" and "similar to tactical problem-solving aimed at coming up with an immediate solution to deal with a stressful problem or situation". In essence, stress tolerance can withstand and deal with adverse events and stressful situations without getting overwhelmed by actively and positively coping with stress (BarOn, 2013). Bar-On identifies this factor of EI to be the one that enables people to face problematic situations rather than avoiding them. It enables one to cope up with environmental demands and also to improve situations. Otherwise, it may result in anxiety and tension. 
Withstanding and overcoming the various stressors requires a high level of stress tolerance mechanism from teachers to be competent enough to recognize the barriers in teaching. Preparing an Individualized Educational Plan or collaborating with others helps to tolerate the stress in them and is vital in an Inclusive Educational Practice. Brackenreed (2011) identified that 1) maintaining a sense of humor, 2) drawing on past experiences, 3) making a plan of action and following it, 4) looking on the bright side, 5) developing interests outside of school, 6) engaging in physical activities and 7) discussing the situation with colleagues as some of the most valuable coping strategies to overcome stress in inclusive classrooms.

Likewise, Pickering (2008) highlighted the methods used by teachers that include prioritizing tasks, longer-term lesson planning, skim-reading assignments; decreasing involvement in extracurricular activities; pooling resources with other teachers and; delegation of tasks for managing workloads.

\section{Impulse Control}

Impulse control is "an ability to effectively and constructively control emotions" and also as "the ability to resist or delay an impulse or temptation to act; and it assumes a capacity for accepting one's aggressive impulses as well as controlling hostile and potentially irresponsible behavior" (Bar-On, 2013). It represents the fourth foundation stone of emotional intelligence after self-awareness, empathy and assertiveness. Impulse control is necessary to any teacher as controlling one's own emotions is expected to sustain a smooth relationship with any fellow being. But it always remains challenging and demanding for teachers in adverse situations. Failure to control one's negative impulses will result in "low frustration tolerance, impulsiveness, anger control problems, abusiveness, loss of self-control and explosive and unpredictable behavior", which can lessen one's ability for conflict resolution and effective leadership.

Zembylas (2005) argues that a teacher plays a part in one's emotional control. Strategies like being a reflective practitioner will help the teachers in knowing and controlling their negative impulses. Being reflective is a self-management strategy to solve problems or in short, one can be reflective of their undesirable behaviors to completely erase it or make it dormant. Teachers can use this reflective strategy to unlearn negative emotions and relearn desirable positive emotions.

\section{Adaptability}

This meta-factor of emotional-social intelligence comprises reality testing, flexibility and problemsolving. Collie and Martin (2016) stated that adaptability is highly relevant to teachers as teaching involves responding to and managing constant changes as teaching work is characterized by experience of change, novelty and uncertainty, so they highlighted that teachers must adapt themselves to 1) respond to students by adjusting lesson pacing, adapting activities, or seeking out new resources to better illustrate main points; 2) respond to unexpected classroom management situations by keeping in check emotions that might arise and thinking of alternative ways to solve problems; 3) interact with new colleagues, parents and students; 4) adjust teaching plans according to the societal demands; 5) integrate new knowledge from professional learning into teaching practice.

Thus they define adaptability as being able to effectively adapt and respond to these new changing or uncertain situations and events. Thus it involves one's capacity to modify one's thinking, behavior and emotions to deal with new, changing or uncertain situations (Collie and Martin, 2016). Their research concluded that teachers with higher adaptability were tended to show higher rates of their well-being, work commitment and students' success.

\section{Reality Testing}

This factor of EI refers to an ability to objectively validate one's feelings and thinking with external reality and tuning in to the immediate situation, attempting to keep things in correct perspective and experiencing things as they are without excessive fantasizing or daydreaming about them (BarOn, 2013). It is an important factor of emotional intelligence which states the perceptual clarity that is closely related to situational awareness. Thus, this sub factor stresses the need for practical and objective ways of obtaining an expected goal. This particular factor enhances those 'practice-based reasons' for 
promoting inclusive education. Engelbrecht et al. (2015) mention the barriers for inclusive education may arise from different levels ranging from lack of financial resources to human resources, where the teacher has to undergo mind shifts in terms of what, why and how to teach by responding to the contexts.

Thus, if the teacher needs to have an understanding of what is inclusive education and how to practice it, they need to perceive the ground realities along with environmental needs with clarity and accuracy combined with 'situational awareness' which are part and parcel of this particular factor of emotional intelligence. To practice inclusion, teachers should be aware of the policies and the available resources in their respective schools with the presence of mind.

\section{Flexibility}

This is an ability to adapt and adjust our feelings, thinking and behavior to new situations and conditions, i.e., one's overall ability to adapt to unfamiliar, unpredictable and dynamic circumstances (Bar-On, 2013). A teacher should react to change without rigidity for their students, especially in inclusive classroom. The lack of flexibility indicates the rigidity in their behavior and it will negatively affect the teacher competency.

Individual challenges and constraints of some students can hinder their teaching-learning process in an inclusive setting. The principle of inclusive practices ensures that a student's commitment to learning is not affected by any form of obstacles. This can be promoted by providing alternative options for learning without compromising appropriate standards. The alternative options can be offered in the form of flexibility, variety and choice in a transparent, fair and equitable manner to the students by the teachers. Teachers should cater to the diverse needs of students by offering flexibility, variety and choice through the use of technology, variety in teaching strategies and choice and flexibility in assessment requirements.

In inclusive classrooms, the teachers should be active enough to offer a flexible curriculum framework, flexible hours and flexible place to learn. At the same time, they should depict flexible attitudes and values towards differences in students. As the principle of inclusive education does not warrant segregation, the teachers shall be free enough to give one to one individual attention and offer special education services according to the learner's needs.

\section{Problem Solving}

It is an "ability to effectively solve problems of a personal and interpersonal nature entailing the ability to identify and define problems as well as to generate and implement potentially effective solutions" (Bar-On, 2013). According to him, problem solvers are often conscientious, disciplined, methodical and systematic in persevering and approaching challenging situations. The multi-phasic nature of this factor includes: dealing with problems, defining and formulating problems and gathering relevant information, generation of possible solutions and implementing the best solution. He clarifies that this process can be enhanced if previous knowledge is utilized to select the best solution, which helps in effective strategic planning. Orgoványi-Gajdos (2016) noted that teachers solve problems not only during the interactive classroom teaching phase but also when they evaluate the previous lesson and plan for the next, i.e., through reflection.

Likewise, Giangreco, Cloninger, Dennis, and Edelman (1994) discussed that the problem solvers would possess the characteristics such as they believe everyone is creative and can solve problems, 2. they are optimistic, 3. they alternate between divergent and convergent thinking, 4. they actively defer and engage their judgment, 5. they encourage "freewheeling" and fun and, 6. they take action.

Thomson, Brown, Jones, Walker, Moore, Anderson, Davies, Medcalf, Glynn, Koegel (2003), in their research, found that the resource teachers engaged in inclusive classrooms practices collaborative problem-solving strategy to overcome challenges they faced. Also, Dubow and Tisak (1989) say that problem-solving combined with social support can play a vital role in dealing with stressors that may interfere in their work.

Snell and Janney (2000) identified that teachers used a process like (a) primarily during the school day whenever they had a free moment; (b) in pairs, small groups, or alone; and (c) repeated it until feasible solutions were determined to solve the concerns of children with moderate and severe disabilities in elementary classrooms. 


\section{General Mood}

This meta-factor of emotional-social intelligence comprises optimism and happiness. It determines one's ability to enjoy themselves, others and life in general and influences one's general outlook on life and overall feeling of contentment. David Wechsler argues that optimism combined with positive mood constitutes conative factors leading to intelligent behavior.

\section{Optimism}

Optimism is defined as our ability to maintain a positive and hopeful attitude toward life even in the face of adversity (Bar-On, 2013). Hoy et al. (2006) defined teacher academic optimism as a positive belief that he or she can make a difference in the academic performance of students by emphasizing academics and learning, by trusting parents and students to cooperate in the process, and by believing in his or her capacity to overcome difficulties and react to failure with resilience and perseverance.

Bar-On explains the links optimism can have with self-motivation, a quality necessary for any goaloriented endeavor (Bar-On, 2013). Moberg (2003) highlighted that teachers feeling sure about their professional skills and have positive experiences of inclusion are more positive towards inclusion. The construct of academic optimism is an offshoot of this factor of inclusive education and it can be defined as "individual teachers' beliefs that they can teach effectively, their students can learn, and parents will support them so the teacher can press hard for learning" (Beard et al., 2010).

A study by Hoy et al. (2006) vindicates the need to have academic optimism by teachers and other stake holders as it is positively linked with students' achievements. Also, Pajares (1996) found that optimistic teachers focus on the positive qualities of the students, classroom, schools and communities.

Ekeh and Njoku (2014) in their study, determined that inclusive school was rated high in academic optimism. Also, students possessed high levels of academic motivation and emotional competence in an inclusive school setting. One of the probable reasons for this would be teachers' optimistic attitude towards inclusive schooling.

\section{Happiness}

Happiness represents the ability to feel content with oneself, others and life in general (Bar-On, 2013). It enables an individual to be self-satisfied with what they do and enjoy it. Rather than being a core factor of EI, happiness combined with selfactualization functions as a fuel for other factors of EI. Along with enhancing motivation, this factor in a relevant degree can contribute towards motivating oneself and also to measure the magnitude of the same. An absence of such a feeling can lead an individual to the dissatisfaction of action and discontent (BarOn, 2013). He elucidated that happiness provides two basic functions of human performance, the first is motivational and the second is barometric. The first one helps to enhance performance by motivating and energizing us, while the latter tells us how well we have performed and can lead to a general sense of well-being. The philosopher Aristotle cited that 'happiness is the meaning and purpose of life, the whole aim and end of human existence' (Meleisea, 2016).

Positive Psychology, popularly referred to as the 'science of happiness', recognizes several 'character strengths' that enhance happiness such as creativity, perseverance, kindness and teamwork, among many others (Meleisea, 2016).

Budiyanto, Sheehy, Kaye and Rofiah (2018), in their research, found that the importance of Suka as a culturally mediated intrinsic part of Indonesian inclusive pedagogy. The teachers who participated in their research interview discussed the relationship between happiness and learning as an essential feature of (inclusive) classroom pedagogy. The teachers used two terms in referring to happiness Senang and Suka, the former being a general term for individualized happiness and the latter focusing on a 'networked' emotion, which is part of social interaction. Budiyanto et al. (2018) observed that this happiness was not seen as a peripheral effect but a central feature of an effective inclusive classroom.

Bullough discussed the influence of hope and happiness on school improvement, where he emphasized that to avoid disenchantment, one has “...to build hope and maximize teacher happiness necessitates work conditions that enhance agency and pathways and, importantly, encourage engagement 
and invite and inspire self-transcendence. Teachers need to be encouraged to do what they believe is best for children and build to their strengths" (Bullough, 2011). Admitting such an effort is not solely in the hands of teachers only, one shall agree with the author that such a eudemonic atmosphere can be productive in a classroom.

\section{Conclusion}

Schonert-Reichl (2017) well documented that teachers are the engine that drives social and emotional skills and practice in school and classroom. Further, she ensued that teachers' socio-emotional competence and well-being strongly influence their students. When teachers poorly manage the social and emotional demands of teaching, students' both academic achievement and behavior will suffer. It is clear that emotionally competent individuals are expected to recognize, manage, and use their emotions to eliminate the ensuing obstacles and advance their career horizons better than people with low emotional intelligence (Carmeli, 2003).

Milovanovi et al. (2016) stressed that teachers should possess an entire range of social competencies and underlined that role of every teacher in the teaching process depends on social competencies in one or the other forms.

Also, the readers of this review will be observing the strong relationship existing between each of the Meta and sub-factors of emotional intelligence. Mastery of one EI factor will assist or develop the other sub-factors which is an advantage to the teachers to enhance their emotional competencies.

Further, from the above review, one can easily conclude that teachers with the Meta and subfactors of emotional intelligence in higher rates will demonstrate resiliency in response to negative stress and are less likely to overwhelm themselves with pessimism and strong negative emotions. As inclusion demand inputs not only from individuals but also from the collaborative venture of teachers, students, parents and community people, it is well taken and justified that teachers should possess emotional competencies to make the IE possible and successful.

\section{References}

Abu, Fadia Nasser-Abu. "Teacher Stress and Coping: The Role of Personal and Job Characteristics." Procedia-Social and Behavioral Sciences, vol. 185, 2015, pp. 374-380.

Addressing Exclusion in Education: A Guide to Assessing Education Systems towards more Inclusive and Just Societies, UNESCO, 2012.

Aliakbari, Mohammad, and Bafrin Bozorgmanesh. "Assertive Classroom Management Strategies and Students' Performance: The Case of EFL Classroom." Cogent Education, vol. 2, no. 1, 2015.

Allan, Julie. "Responsibly Competent: Teaching, Ethics and Diversity." Policy Futures in Education, vol. 9, no. 1, 2011, pp. 130-137.

Amoriello, Theresa. "Promoting Empathy in an Inclusive Special Education Classroom." Medium, 2018.

Andrew, Boon. "The Reflective Teacher, Towards Self-Actualization." The language teacher, vol. 35 , no. 4 , 2011, pp. 27-30.

Bar-On, Reuven. "The 15 factors of the Bar-On model." http://www.reuvenbaron.org/wp/the5-meta-factors-and-15-sub-factors-of-thebar-on-model.

Bar-On, Reuven. "The Bar-On Model of EmotionalSocial Intelligence (ESI)." Psichotema, vol. 18, 2006, pp. 13-25.

Beard, Karen Stansberry, et al. "Academic Optimism of Individual Teachers: Confirming a New Construct." Teaching and Teacher Education, vol. 26, no. 5, 2010, pp. 1136-1144.

Billingsley, Bonnie S. Special Education Teacher Retention and Attrition: A Critical Analysis of the Literature, Center on Personnel Studies in Special Education, University of Florida, 2003.

Brackenreed, Darlene. "Inclusive Education: Identifying Teachers' Strategies for Coping with Perceived Stressors in Inclusive Classrooms." Canadian Journal of Educational Administration and Policy, no. $122,2011$.

Budiyanto, et al. "Developing Signalong Indonesia: Issues of Happiness and Pedagogy, Training and Stigmatisation." International Journal 
of Inclusive Education, vol. 22, no. 5, 2018, pp. 543-559.

Bullough, Robert V. "Hope, Happiness, Teaching, and Learning." New Understandings of Teacher's Work, edited by Christopher Day and John Chi-Kin Lee, Springer, 2011, pp. 15-30.

Carmeli, Abraham. "The Relationship between Emotional Intelligence and Work Attitudes, Behaviour and Outcomes." Journal of Managerial Psychology, vol. 18, no. 8, 2003, pp. 788-813.

Dubow, E. F. and J. Tisak. "The Relation between Stressful Life Events and Adjustment in Elementary School Children: The Role of Social Support and Social Problem-Solving Skills." Child Development, vol. 60, no. 6, 1989, pp. 1412-1423.

Ekeh, P.U., and C. Njoku. "Academic Optimism, Students Academic Motivation and Emotional Competence in an Inclusive School Setting." European Scientific Journal, vol. 10, 2014, pp. 127-141.

Engelbrecht, Petra, et al. "Enacting Understanding of Inclusion in Complex Contexts: Classroom Practices of South African Teachers." South African Journal of Education, vol. 35, no. 3, 2015, pp. 1-10.

Fan, F. A. 'Teacher: Students' Interpersonal Relationships and Students' Academic Achievements in Social Studies." Teachers and Teaching: Theory and Practice, vol. 18, no. 4, 2012, pp. 483-490.

Florian, L. "Editorial." Journal of Research in Special Educational Needs, vol. 10, 2010, pp. 137-138.

Forlin, Chris. "Inclusion: Identifying Potential Stressors for Regular Class Teachers." Educational Research, vol. 43, no. 3, 2001, pp. 235-245.

Giangreco, Michael F., et al. "Problem-Solving Methods to Facilitate Inclusive Education." Creativity and Collaborative Learning: A Practical Guide to Empowering Students and Teachers, edited by J.S. Thousand, et al., P.H. Brookes Publishing Company, 1994, pp. 321-346.
Goleman, Daniel. Working with Emotional Intelligence, Bantam Books, 1998.

Greenway, Rosanne, et al. "Autonomy and Accountability: Teacher Perspectives on Evidence-Based Practice and DecisionMaking for Students with Intellectual and Developmental Disabilities." Education and Training in Autism and Developmental Disabilities, vol. 48, no. 4, 2013, pp. 456-468.

Hoy, Wayne K., et al. "Academic Optimism of Schools: A Force for Student Achievement." American Educational Research Journal, vol. 43, no. 3, 2006, pp. 425-446.

Jena, Prakash Chandra, and Rinzin Dorji. "Selfactualization and Value Orientation among Primary School Teachers in Bhutan." World Scientific News, vol. 54, 2016, pp. 217-239.

Jorfi, Hassan, et al. "Emotional Intelligence: The Relationship between Self-Regard and Communication Effectiveness." International Journal of Psychological and Behavioral Sciences, vol. 4, no. 9, 2010, pp. 1989-1995.

Leminen, Anu. Self-concept of Children in Special and Regular Education, University of Jyväskylä, 2002.

Loreman, Tim, et al. "Conceptualizing and Measuring Inclusive Education." Measuring Inclusive Education: Volume 3, Emerald Group Publishing Limited, 2014, pp. 3-17.

Martínez, Villena, et al. "Teacher Assertiveness in the Development of Students' Social Competence." Electronic Journal of Research in Educational Psychology, vol. 14, no. 2, 2006, pp. 310-332.

Maslow, Abraham H. Motivation and Personality, Harper \& Row, Publishers, Inc., 1954.

Mayer, John D. and Peter Salovey. "What is Emotional Intelligence?" Emotional Development and Emotional Intelligence: Implications, Basic Books, 1997, pp. 3-34.

Meijer, C.J.W. Trends in Provision in 18 European countries, European Agency for Development in Special Needs Education, 2003.

Meleisea, Ellie. Happy Schools: A Framework for Learner Well-Being in the Asia-Pacific, United Nations Educational, Scientific and Cultural Organization, 2016. 
Michali, Y. E. Increasing Teacher Awareness of Self-Determination, Kent State University College of Education, Health, and Human Services, 2014.

Milovanovi, Radmila, et al. "Assertiveness of Prospective Teachers and Preschool Teachers." Journal Plus Education, vol. 16, 2016, pp. 289-303.

Minondo, Stacey, etal. "The Role and Responsibilities of Teaching Assistants in Inclusive Education: What's Appropriate?" Research and Practice for Persons with Severe Disabilities, vol. 26, no. 2, 2001, pp. 114-119.

Moberg, Sakari. 'Education for all in the North and the South: Teachers' Attitudes towards Inclusive Education in Finland and Zambia." Education and Training in Developmental Disabilities, vol. 38, no. 4, 2003, pp. 417-428.

Opić, Siniša. "Interpersonal Relations in Schools." International Journal of Cognitive Research in Science, Engineering and Education, vol. 4, no. 2, 2016, pp. 9-21.

Orgoványi-Gajdos, Judit. "Problem Solving as a Cross-Curricular Skill of Teachers." Teachers' Professional Development on Problem Solving, Sense Publishers, 2016, pp. 1-7.

Pajares, Frank. "Self-efficacy Beliefs in Academic Settings." Review of Educational Research, vol. 66, no. 4, 1996, pp. 543-578.

Pantic, Natasa, and Lani Florian. "Developing Teachers as Agents of Inclusion and Social Justice." Education Inquiry, vol. 6, no. 3, 2015.

Parchomiuk, Monika. "Teacher Empathy and Attitudes towards Individuals with Disabilities." International Journal of Disability Development and Education, vol. 66, no. 1, 2019, pp. 56-69.

Partridge, Erica J. Empathy in Inclusive Classrooms: Exploring Pro-social Behaviour Through Children's Academic Writing Skills, The University of Western Ontario, 2018.

Poornima, R. Emotional Intelligence, Occupational Stress and Job Satisfaction of Special Education Teachers, Discovery Publishing House, 2012.
Poornima, Rajendran. An Assessment of Teacher Training Programmes in Norway with Special Reference to Inclusive Education. Project submitted to Research Council of Norway, 2012.

Rapheal, Jeny, and K Varghese Paul. "SelfActualization and Personal Growth Initiative among the Teachers of Adolescents." Scopus, vol. 2, no. 2, 2012, pp. 61-72.

Reddy, G. Lokanadha. Occupational Stress, Professional Burnout and Job Satisfaction of Special Education Teachers', Project submitted to Ministry of Social Justice and Empowerment, Govt. of India, 2007.

Richardson, Brent G., and Margery J. Shupe. "The Importance of Teacher Self-Awareness in Working with Students with Emotional and Behavioral Disorders.” Teaching Exceptional Children, vol. 36, no. 2, 2003, pp. 8-13.

Sabrina, Nadia, and Sansrisna. Teachers' Beliefs in Practicing Inclusive Education: Case Study of Elementary Schools in Banda Aceh, University of Tampere, 2017.

Schonert-Reichl, Kimberly A. "Social and Emotional Learning and Teachers." The Future of Children, vol. 27, no. 1, 2017, pp. 137-155.

Secret Teacher: There is No Autonomy in Teaching Today, The Guardian, 2013.

Slee, Roger. "Political Economy, Inclusive Education and Teacher Education." Teacher Education for Inclusion: Changing Paradigms and Innovative Approaches, edited by Chris Forlin, Routledge, 2010.

Snell, Martha E., and Rachel E. Janney. "Teachers' Problem-Solving about Children with Moderate and Severe Disabilities in Elementary Classrooms." Exceptional Children, vol. 66, no. 4, 2000, pp. 472-490.

Sprenger, Terezinha Maria, and Maria Paula Salvador Wadt. "Autonomy Development and the Classroom: Reviewing a Course Syllabus." DELTA, vol. 24, 2008, pp. 551-576.

Stojiljković, Snežana. "Empathy and Teachers' Roles." Procedia - Social and Behavioral Sciences, vol. 69, 2012, pp. 960-966.

Teacher Education for Inclusion across Europe - Challenges and Opportunities, European 
Agency for Development in Special Needs Education, 2011.

Tettegah, Sharon, and Carolyn J.Anderson. "PreService Teachers' Empathy and Cognitions:

Statistical Analysis of Text Data by Graphical Models." Contemporary Educational Psychology, vol. 32, no. 1, 2007, pp. 48-82. Thomson, Charlotte, et al. "Resource Teachers Learning and Behavior: Collaborative Problem Solving to Support Inclusion." Journal of Positive Behavior Interventions, vol. 5, no. 2, 2003, pp. 101-111.
Vagos, Paula, and Anabela Pereira. "A Proposal for Evaluating Cognition in Assertiveness." Psychological Assessment, vol. 22, no. 3, 2010, pp. 657-665.

Yate, Martin. CareerSmarts: Jobs with a Future, Ballantine Books, 1997.

Zembylas, Michalinos. "Discursive Practices, Genealogies, and Emotional Rules: A Poststructuralist View on Emotion and Identity in Teaching." Teaching and Teacher Education, vol. 21, no. 8, 2005, pp. 935-948.

\section{Author Details}

Poornima Rajendran, Assistant Professor, Department of Education, Central University of Tamil Nadu (Neelakudi Campus),Thiruvarur, Tamil Nadu, India, Email ID: poornimarajendran@cutn.ac.in

B.K.Athira, Research Scholar, Centre for the Study of Social Systems, Jawaharlal Nehru University, New Delhi, Email ID: athirakalithozhi@gmail.com

D. Elavarasi, Research Scholar, Department of Education, Central University of Tamil Nadu (Neelakudi Campus), Thiruvarur, Tamil Nadu, India, Email ID:dp.elavarasi@gmail.com 